Revista em Agronegócio e Meio Ambiente, Maringá (PR)

DOI: http://dx.doi.org/10.17765/2176-9168.2017v10n1p167-190

\title{
OS DESAFIOS DA INDÚSTRIA FARMACÊUTICA BRASILEIRA DIANTE DA POLÍTICA NACIONAL DE RESÍDUOS SÓLIDOS
}

\author{
Roger Augusto Luna" \\ Fernando Luiz Emerenciano Viana**
}

\begin{abstract}
RESUMO: Produtos farmacêuticos são amplamente utilizados pela população, porém, a devida atenção ao processo de retorno de seus resíduos não é tratada de forma adequada, abrindo espaço para que ocorram impactos ambientais devido a isto. Este artigo tem como objetivo analisar a influência da Política Nacional dos Resíduos Sólidos (PNRS), Lei federal $\mathrm{n}^{0}$ 12.305/2010, na logística reversa da indústria farmacêutica de medicamentos com uso domiciliar, constituindo um estudo qualitativo de caráter descritivo, que envolveu a realização de entrevistas com os gestores de empresas fabricantes de medicamentos, além de análise documental das leis em vigor sobre o tema. Os resultados indicam que a indústria farmacêutica ainda não está adequadamente preparada para atender ao que está estabelecido na PNRS, embora já exista uma articulação com seu sindicato de classe para que isto ocorra em breve.
\end{abstract}

PALAVRAS-CHAVE: Logística reversa; Medicamentos de uso doméstico; Política Nacional de Resíduos Sólidos (PNRS).

\section{THE CHALLENGES OF PHARMACEUTICAL INDUSTRY IN THE WAKE OF THE BRAZILIAN POLICY FOR SOLID WASTES}

ABSTRACT: Although pharmaceutical products are widely used by the population, proper attention to residue disposal is not adequate and several environmental impacts may occur. Current study analyzes the influence of the Brazilian Policy for Solid Wastes, Law 12305/2010, within the reverse logistic of the pharmaceutical industry for medicines used in the home. The qualitative and descriptive analysis involves interviews with managers of medicine-producing companies and a study of the laws on the theme. Results show that the pharmaceutical industry is not yet adequately prepared to attend to the Brazilian Policy for Solid Wastes, even though means are being implanted for this purpose.

KEY WORDS: Reverse logistics; Home medicines; Brazilian policy for solid wastes (PNRS).

\footnotetext{
Docente Pesquisador do Grupo de Pesquisa Núcleo de Estudos de Estratégias em Sustentabilidade (NESS); Universidade de Fortaleza (UNIFOR), Ceará, Brasil; E-mail de correspondência: rog_luna@hotmail.com

** Docente Doutor no Programa de Pós Graduação em Administração de Empresas (PPGA) Universidade de Fortaleza (UNIFOR), Ceará, Brasil.
} 


\section{INTRODUÇÃO}

Percebe-se que o atual modelo de negócio das empresas, o meio ambiente, passou a ser um fator importante e estratégico. A quebra de paradigmas e a introdução de novos modelos de gestão têm dado às empresas um novo caminho a trilhar. Para Araújo e Gava (2011), a quebra de paradigmas ocorrerá na medida em que novos lançamentos de produtos com orientação à sustentabilidade do meio ambiente estiverem atendendo às demandas dos consumidores.

De acordo com Attaran e Attaran (2007), a demanda dos consumidores por melhores níveis de serviço, o que representa ter o direito de ter produto nas prateleiras, isto é, disponíveis a qualquer momento, está aumentando.

Rogers e Tibben-Lembke (2001) analisaram que no retorno de produtos uma alta porcentagem é apontada pelas devoluções de clientes, representando aproximadamente $6 \%$ do total de mercadorias vendidas, embora as taxas de retorno variem de forma significativa pela indústria.

Barreiras tais como política da empresa, ausência de sistemas informatizados, falta de legislação, limitações de recursos financeiros, são citadas como dificuldades no gerenciamento dos retornos. Na medida em que as devoluções de produtos são fatos do dia a dia das organizações, a logística reversa passa a demonstrar maior atenção e cuidado por parte dos gestores (STOCK, 2007).

De acordo com Kumar e Putnam (2008), os fabricantes vêm experimentando as pressões governamentais de forma reguladora, através de leis e normas para as questões socioambientais relativas às embalagens provenientes do pós-venda, em que se poderia investir em um processo de logística reversa mais satisfatório.

Observa-se que a geração de resíduos é uma realidade vivida por várias empresas, entre estas, as farmacêuticas. O descarte incorreto de resíduos de medicamentos, sobras ou vencidos, realizados pelos consumidores finais tem gerado grandes impactos ao meio ambiente. Para Kumar, Dieveney e Dieveney (2009), devido à gravidade potencial da utilização de medicamentos expirados ou ineficazes, é fundamental que as empresas farmacêuticas se aliem aos processos de logística reversa desde o início do seu processo de venda.

Ademais, o descarte inadequado de medicamentos impõe riscos 
consideráveis para a saúde humana e para o meio ambiente de uma maneira geral. A geração de resíduos pelas diversas atividades humanas constitui-se atualmente em um grande desafio a ser enfrentado pelas administrações municipais, sobretudo nos grandes centros urbanos. Para Kumar, Dieveney e Dieveney (2009) existem duas causas comuns para os retornos na indústria farmacêutica: medicamentos vencidos e recalls.

Neste contexto, o estabelecimento de um programa de adequado descarte de medicamentos torna-se fundamental e estratégico para as indústrias farmacêuticas, considerando, também, que a logística reversa tem se constituído em algo essencial para a competitividade.

Diversas políticas públicas voltadas para a indústria farmacêutica já fazem parte do cenário internacional, principalmente na Europa, tendo em vista que na Alemanha, Espanha, França, Itália, Portugal e Suécia, a destinação e coleta de resíduos de medicamentos já são regulamentadas (DAUGHTON, 2003a). Os problemas sociais e ambientais relacionados aos resíduos de medicamentos são justificativos para que essas iniciativas fossem implantadas nestes países (DAUGHTON, 2003a; DAUGHTON, 2003b).

Segundo Hiratuka et al. (2013), a comunidade europeia criou programas que utilizam as redes de farmácias e drogarias como pontos centrais de coleta de resíduos e medicamentos vencidos, o que facilita o retorno destes produtos pelo consumidor final.

A importância destacada por Reveilleau (2011, p. 164) para a Política Nacional de Resíduos Sólidos (PNRS), que é a Lei federal nº 12.305/2010, é que ela ultrapassou "um dos obstáculos que era a inexistência de uma norma de âmbito nacional que tivesse como foco principal gerenciar os resíduos, atribuir responsabilidades aos seus geradores, consumidores e ao poder público". Porém, a PNRS não aborda com clareza e especificidade o descarte de resíduos de medicamentos de uso domiciliar.

Nota-se que diversos são os desafios da indústria farmacêutica para os próximos anos, incluindo novos players no mercado, fusões e aquisições, desenvolvimento de novos produtos, processos logísticos mais coerentes com as necessidades que estão sendo demandadas (PALMEIRA-FILHO; CAPANEMA, 2010). Por fim, o mercado ainda está sendo pressionado tanto pelos consumidores, 
como por órgãos públicos, em relação ao descarte correto de seus resíduos e a sustentabilidade ambiental em seus processos.

Assim sendo, esse trabalho tem o objetivo geral de analisar a influência da PNRS na logística reversa da indústria farmacêutica. Para tal, foram delineados os seguintes objetivos específicos: (1) Identificar os fluxos reversos atualmente existentes na cadeia de medicamentos; e (2) Avaliar o papel da indústria farmacêutica no fluxo reverso, à luz da legislação (PNRS) existente sobre o tema.

Para atender aos objetivos propostos, o trabalho está estruturado em cinco tópicos, incluindo esta introdução. O tópico 2 apresenta uma breve contextualização acerca da logística reversa e da PNRS. No tópico 3 são destacados os procedimentos metodológicos utilizados. O tópico 4 apresenta os principais resultados relacionados aos objetivos traçados, enquanto que o tópico 5 traz a conclusão, seguida das referências bibliográficas.

\section{REVISÃO TEÓRICA}

\subsection{CONCEITUAÇÃO E CARACTERIZAÇÃO DA LOGÍSTICA REVERSA}

A evolução do conhecimento e dos processos logísticos fez com que várias barreiras fossem ultrapassadas e ganhos processuais e financeiros fossem gerados. A interdependência gerada na cadeia de suprimentos fez com que as empresas buscassem desenvolver processos de melhorias em seus processos (SEURING et al., 2008). Corroboram com esta ideia Lambert, Cooper e Pagh (1998), quando afirmam que a gestão da cadeia de suprimento oferece a oportunidade para capturar a sinergia de integração e gestão interfirmas, representando uma nova forma de gerir os negócios e os relacionamentos com os demais membros da cadeia de suprimentos.

Contudo, neste processo de evolução, percebeu-se a necessidade do retorno dos produtos ou, não raro, das embalagens ou resíduos gerados, aumentando os custos operacionais. Como aconteceu com a logística, o conceito de logística reversa também evoluiu ao longo do tempo. Inicialmente, em seu conceito mais simples, a logística foi definida como o movimento de materiais do ponto de origem ao ponto de consumo (BALLOU, 1993; BOWERSOX; CLOSS, 2001; NOVAES, 2007). 
A mudança cultural e nos hábitos dos consumidores trazem diversos exemplos do aumento nas quantidades de produtos disponíveis no mercado, com $\mathrm{o}$ intuito de saciar as necessidades dos consumidores. Nesse contexto nota-se a grande possibilidade de produtos retornarem do mercado por diversos motivos, com ou sem uso, dando a visibilidade e a possibilidade da logística reversa atuar como um processo dinâmico e atual. O ciclo de vida dos produtos está cada vez mais reduzido, as constantes renovações de modelos e a utilização de materiais com menor durabilidade têm contribuído para a obsolescência dos mesmos (LEITE, 2003; LEITE, 2010).

Desse modo, introduzir o processo de logística reversa nas empresas tornase inerente ao ciclo da cadeia de suprimentos, pois este irá reintegrar, de alguma forma, o produto aos novos ciclos produtivos e de negócio (LEITE, 2003). Para Strehlau e Telles (2006), a logística reversa, ou canal reverso, possui um fluxo inverso ao de venda, isto é, do consumidor ao produtor, abrindo duas possibilidades de utilização: a) economias derivadas de reciclagem (preocupação com meio ambiente ou exigência legal); b) contingência de call back ou recall de produtos (necessidade de recolher o produto por motivos de qualidade, segurança etc.).

A eficiência da logística reversa dependerá de como as empresas fazem a sua gestão, de como o seu processo é planejado e controlado. Lacerda (2003) identificou alguns fatores como sendo críticos e que contribuem para o desempenho da logística reversa, destacando: bons controles de entrada; processos mapeados e formalizados; ciclo de tempo reduzido; sistemas de informações acurados; rede logística planejada e colaboração entre clientes e fornecedores; além da integração dos operadores logísticos nos processos. $\mathrm{O}$ relacionamento entre estes fatores poderá mensurar $\mathrm{o}$ grau de eficiência do processo de logística reversa.

Segundo Leite (2003), os canais reversos de distribuição podem ser divididos em duas categorias: canais reversos de pós-consumo e canais reversos de pós-venda. Na primeira categoria, estariam classificados os produtos sem utilidade, sendo que os únicos destinos deveriam ser a incineração ou aterros sanitários. Para a segunda categoria, seria destinada aos produtos que de alguma forma, ainda poderiam retornar ao ciclo produtivo, com possibilidade de revenda, remanufatura e a reciclagem. Para Tibben-Lembke e Rogers (2002), a logística reversa é caracterizada 
pelo movimento em direção oposta ao canal de distribuição, tendo como propósito a criação e recaptura de valor, além da correta destinação.

Lambert e Cooper (2000) entendem que o gerenciamento de retornos como um processo do negócio poderá oferecer a mesma oportunidade de se alcançar uma vantagem competitiva sustentável, como se faz no gerenciamento da cadeia de suprimentos a partir da perspectiva de saída. Consoante a isto, Thierry et al. (1995, p. 114) destacam que o objetivo da gestão da recuperação de produtos é o de "resgatar de uma maneira razoável a maior quantidade possível de valores econômicos (e ecológicos) e, consequentemente, reduzir ao mínimo a geração de resíduos”.

Observa-se que a logística reversa é orientada por objetivos estratégicos ou direcionadores que podem trazer vantagens competitivas, além de poderem ser avaliados por diferentes perspectivas. Os direcionadores envolvem diretamente ações em cidadania corporativa, redução de custos, fatores tecnológicos, fatores modificadores, obrigações legais e motivações econômicas (ROGER; TIBBENLEMBKE, 2001; STOCK, 2007; LEITE, 2010).

Para Quintão e Jesus (2011), existem diversas razões que motivam a implantação de processos de logística reversa, as quais se complementam. Determinantes como redução de custos, ganhos de receita, existência de leis ambientais, adequação às questões ambientais, criação de imagem diferenciada da empresa junto ao cliente, contexto social e eficiências do fluxo de materiais justificam a adesão de processos de logística reversa (SEURING et al., 2008).

$\mathrm{Na}$ visão de Dowlatshahi (2000) custo, qualidade, serviço aos clientes, meio ambiente e legislação são aspectos caracterizados como importantes direcionadores para que as empresas estabeleçam procedimentos de logística reversa. A relação que pode existir entre os determinantes dependerá de como a empresa e os seus stakebolders se relacionam com as questões da logística reversa e desenvolvem as suas estratégias (QUINTÃO; JESUS, 2011). No entanto, são poucas as análises que examinam de forma específica o impacto destes direcionadores sobre as políticas de retorno adotadas pelas empresas (DOWLATSHAHI, 2000; ROGER; TIBBEN-LEMBKE, 2001).

A distribuição dos produtos, rotas planejadas, redução no consumo de combustível, entre outras, são entendidas como ações de logística verde, considerando 
que a logística reversa tem o objetivo de buscar um eficiente planejamento no descarte dos resíduos (MISHRA; KUMAR; CHAN, 2012). Segundo Donato (2008), as novas regulamentações ambientais sobre resíduos trazem para as organizações um novo paradigma chamado de logística verde, o que faz com que os gestores sejam responsáveis por implementarem planos e projetos de logística voltados ao atendimento das regulamentações legais. Ademais, reafirma a preocupação das empresas com o ciclo de vida do produto, pois planos inovadores devem atender à duração do produto no mercado e seu retorno à cadeia produtiva.

Consoante a isto, Zhu e Sarkis (2004) afirmam que toda a cadeia de suprimentos verde está relacionada tanto a ações reativas nos programas empresariais de gestão ambiental até às práticas mais proativas, tais como reciclagem, recuperação e logística reversa. Para Srivastava (2007), no conceito da cadeia de suprimentos verde, os efeitos ambientais são vistos e considerados em todos os elos da cadeia de abastecimento, desde a sua origem até o destino final dos produtos, isto é, consumo ou retorno aos canais reversos.

A logística reversa também pode ser considerada um instrumento de desenvolvimento econômico e social, onde a partir de determinadas ações e procedimentos que visam à coleta e restituição dos resíduos sólidos às suas origens, tanto para uma remanufatura, em seu ciclo ou em outros ciclos produtivos, quanto para o descarte final correto (BRASIL, 2010). No Brasil, a PNRS representa um marco para o crescimento do debate sobre logística reversa e iniciativas de redução de poluentes no meio ambiente.

\subsection{POLÍTICA NACIONAL DE RESÍDUOS SÓLIDOS (PNRS)}

A criação da PNRS, que tem como diretriz a gestão dos resíduos sólidos através da redução do montante de resíduos enviados aos aterros, incorporação dos conceitos de responsabilidade compartilhada e de logística reversa, tem objetivo de controlar e direcionar as ações das empresas nas questões de gestão dos resíduos provenientes dos canais reversos de distribuição (BRASIL, 2010).

A PNRS possui a seguinte definição para resíduos sólidos: 
Material, substância, objeto ou bem descartado resultante de atividades humanas, a cuja destinação final está obrigado a proceder, nos estados sólido ou semissólido, bem como gases contidos em recipientes e líquidos cujas particularidades tornem inviável o seu lançamento na rede pública de esgotos ou em corpos d'água, ou exijam para isso soluções técnica ou economicamente inviáveis em face de melhor tecnologia disponível (BRASIL, 2010, p. 2).

Devido à diversidade dos resíduos, faz-se necessário uma classificação por tipo e característica. De acordo com a ANVISA (2004), a RDC 306/2004 estabelece que os Resíduos Sólidos de Saúde podem ou não apresentar componentes de periculosidade e estas características determinam os riscos que podem acarretar ao meio ambiente. Os resíduos são classificados da seguinte forma: Grupo A) Resíduos Biológicos; Grupo B) Resíduos Químicos; Grupo C) Resíduos Radioativos; Grupo D) Resíduos Comuns Recicláveis e Não Recicláveis; Grupo E) Resíduos Perfurocortantes.

Dentre os resíduos gerados, destacam-se os do Grupo B, resíduos químicos, entre os quais se enquadram os resíduos de medicamentos (vencidos, contaminados, interditados ou não utilizados). Esta segregação por grupos também orienta no momento do descarte correto do material. Os resíduos classificados no Grupo B têm como recomendação de seu destino final a incineração, não devendo ter seu descarte em aterro sanitário (BRASIL, 2006).

A determinação da PNRS é clara sobre o descarte de resíduos sólidos e suas obrigações, mas não aborda o devido descarte em relação ao consumidor final de medicamentos de uso domiciliar. Apesar de considerar o consumidor como um gerador de resíduos, a PNRS apenas indica que ações de responsabilidade compartilhada aos envolvidos ao longo da cadeia de suprimentos devem ser praticadas, definindo como responsabilidade compartilhada um

Conjunto de atribuições individualizadas e encadeadas dos fabricantes, importadores, distribuidores e comerciantes, dos consumidores e dos titulares dos serviços públicos de limpeza urbana e de manejo dos resíduos sólidos, para minimizar o volume de resíduos sólidos e rejeitos gerados, bem como para reduzir os impactos causados à saúde humana e à qualidade ambiental decorrentes do ciclo de vida dos produtos, nos termos desta Lei (BRASIL, 2010, p. 2). 
Alguns objetivos para a responsabilidade compartilhada pelo ciclo de vida do produto foram determinados para o atendimento da PNRS. Os objetivos da responsabilidade compartilhada visam fazer com que os envolvidos na cadeia de suprimentos interajam entre si e executem as ações para o retorno e descarte correto dos resíduos sólidos. Neste caso, a Lei $\mathrm{n}^{\mathrm{o}}$ 12.305/2010, art. 33, § 1 obriga todos os fabricantes, distribuidores e comerciantes de produtos comercializados em embalagens plásticas, metálicas ou vidros a estruturar e implementar sistemas de logística reversa, ou seja, devolver as embalagens ao fabricante que, por sua vez, deve dar um destino ambiental adequado de forma independente do serviço público de limpeza urbana.

As indústrias precisam se organizar para a execução destes novos requisitos da PNRS, tanto no âmbito da logística reversa, quanto no desenvolvimento de novas embalagens.

\section{PROCEDIMENTOS METOdOLÓGICOS}

Este estudo possui uma abordagem qualitativa. De acordo com Denzin e Lincoln (2006), a pesquisa qualitativa abrange o estudo do uso e a coleta de diversos materiais empíricos.

Para a obtenção e coleta de dados, foi utilizada a entrevista, o que facilita alcançar o objetivo geral de analisar a influência da PNRS na logística reversa da indústria farmacêutica de medicamentos de uso domiciliar, já que possibilita interpretar as informações coletadas.

Foi elaborado um roteiro com perguntas semiestruturadas, objetivando a compreensão do entrevistado, levando em consideração sua opinião sobre a temática em questão (GASKELL, 2002; BONI; QUARESMA, 2005). A pesquisa também terá caráter descritivo, o que segundo Godoy (1995b) faz parte das características da pesquisa qualitativa. Os critérios de inserção dos sujeitos foram baseados na visão de Cooper e Schindler (2003), que estabelecem que os respondentes devam ser aqueles que possuem as informações e conhecimento sobre o objetivo da pesquisa e da questão-problema. 
Por se tratar de um tema complexo e novo para as indústrias, o universo de pesquisa será delimitado e focado na indústria farmacêutica com atuação nacional, devido à sua importância na cadeia de suprimentos, já que é a responsável pela fabricação e venda dos produtos fármacos para o restante da cadeia de suprimentos.

A escolha das empresas deu-se através de três critérios: i) distribuição em nível nacional; ii) possuir medicamentos disponíveis no varejo (farmácias); iii) acesso à empresa. Foi garantido nesse processo que as identidades dos entrevistados, bem como das respectivas organizações, seriam preservadas e mantidas em sigilo (GASKELL, 2002). Com isto, foram utilizados para a identificação dos respondentes as seguintes classificações: Empresa 1 (E1), Empresa 2 (E2) e Empresa 3 (E3) e Sindusfarma.

As entrevistas foram realizadas entre os meses de fevereiro e março de 2014. No total foram entrevistados quatro sujeitos, sendo três deles de empresas industriais, que ocupam cargos relacionados à gestão de logística, além de um representante do Sindicato da Indústria Farmacêutica do Estado de São Paulo (SINDUSFARMA).

$\mathrm{Na}$ elaboração do roteiro, optou-se por fundamentá-lo através do referencial teórico utilizado pelos autores, com isso identificou-se assuntos-chave para o direcionamento das entrevistas: nível de atuação da empresa, como está estruturado o fluxo reverso, componentes da cadeia de suprimentos da indústria farmacêutica, papel dos fabricantes de medicamentos no atendimento à PNRS, desafios para atendimento e implementação da política. As entrevistas foram transcritas e, após as primeiras leituras de exploração, foram organizadas de forma que viabilizaram a préanálise e estabeleceram um esquema de trabalho. Assim sendo, foi utilizada a análise de conteúdo, que segundo Godoy (1995a), possibilita ao pesquisador compreender as características, estruturas e modelos que estão compondo a o conteúdo a ser estudado.

Como suporte ao tratamento de dados, foi utilizado o software Atlas.ti, no qual foram especificadas as categorias de análise, o que facilitou a compreensão e a exploração das respostas obtidas durante as entrevistas, além da credibilidade nos dados apresentados (COOPER; SCHINDLER, 2003). Também foram utilizados recursos técnicos, tais como figuras e quadros para facilitar a compreensão dos pesquisadores e interessados no tema. 


\section{ANÁLISE DOS RESULTADOS}

Nesta seção serão demonstrados os resultados das análises obtidas através da pesquisa de campo. Para isto, a análise foi dividida em quatro subitens, resultando também no atendimento dos objetivos propostos nesta pesquisa.

\subsection{CARACTERÍSTICAS E NÍVEIS DE ATUAÇÃO DAS EMPRESAS}

As empresas pesquisadas são fabricantes de medicamentos com uso domiciliar. São multinacionais de médio e grande porte, possuindo plantas produtivas tanto no Brasil, quanto no exterior, com abrangência de comercialização nacional e grande penetração no mercado consumidor. Os produtos comercializados estão relacionados a terapias com medicamentos sob prescrição e isentos de prescrição, psiquiatria, dermatologia e nutracêuticos.

As empresas entrevistadas estão localizadas no Estado de São Paulo, algumas possuindo plantas produtivas no interior e escritório na capital, porém a distribuição e o planejamento logístico são aplicados para todo o território nacional. Os processos de logística reversa das empresas pesquisadas são gerenciados por gerentes de logística, em muitos casos subordinados a uma área de Supply Chain Management (SCM). Devido à complexidade e extensão da cadeia de suprimentos, a indústria farmacêutica trabalha com diversos parceiros, que compõem os elos desta cadeia, para fazer com que o produto chegue ao cliente final.

\subsection{ESTRUTURA DA CADEIA DE SUPRIMENTOS DE MEDICAMENTOS E SEU FLUXO REVERSO}

Nesta pesquisa foi identificada uma extensa cadeia de suprimentos, envolvendo diversos elos e atores no processo ligado à fabricação, distribuição e venda, até chegar ao consumidor final. Estes elos trocam informações sobre estoques nos canais e necessidade de abastecimento, criando uma sinergia e integração entre os participantes da cadeia de suprimentos, corroborando assim com as teorias de Lambert, Cooper e Pagh (1998), além de Seuring et al. (2008).

A indústria farmacêutica possui com seus fornecedores um vínculo de 
troca de informações para o abastecimento contínuo dos estoques (BALLOU, 1993; CHEN; PAULRAJ, 2004; ATTARAN; ATTARAN, 2007), o que se confirma também no discurso da Empresa 1 (E1): [...] "hoje a empresa tem quatro plantas espalhadas pelo mundo que nos abastecem e essas quatro plantas trazem aqui para a fábrica e fazemos o processo seguinte de distribuição "[...].

Já na parte a jusante da cadeia, a partir da indústria farmacêutica, que constitui o núcleo principal de análise, foram identificados dois grandes elos na cadeia, trabalhando muitas vezes interníveis para o atendimento da cadeia, corroborando com Lambert, Cooper e Pagh (1998) sobre as relações entre os elos da cadeia. Os distribuidores são responsáveis pelo abastecimento das pequenas farmácias e grandes redes de farmácias, com os quais a indústria farmacêutica também pode comercializar.

Já para o fluxo reverso, identificou-se que, para todos os fabricantes de medicamentos, existe um processo estabelecido. Este processo estabelecido pela indústria determina o retorno de produtos vencidos ou rejeitados no momento da entrega, conforme as observações feitas pelas empresas durante a entrevista, E1: "o que temos hoje sobre logística reversa se refere a produtos com data de validade próxima ao vencimento, que segue a política da companhia, ou produtos rejeitados no recebimento de uma carga".

Observa-se na Figura 1 a existência de um fluxo de retorno dos medicamentos, porém, apenas para um processo em que os produtos se encontrem vencidos ou avariados.

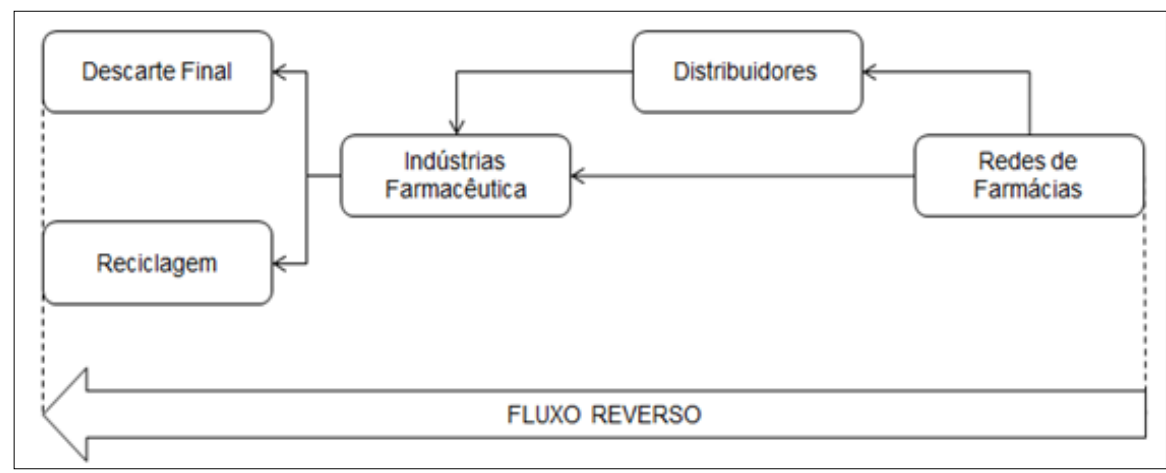

Figura 1. Fluxo Reverso de Medicamentos

Fonte: Elaborado pelos autores (2014). 
O fator tempo torna-se um direcionador da logística reversa da cadeia de suprimentos neste processo, uma vez que há grande preocupação em não gerar devoluções ou movimentações de entrega desnecessárias, possuindo processos mais eficientes no fluxo da cadeia de abastecimento, confirmando os achados de pesquisa de Quintão e Jesus (2013):

E1: É um política comercial não uma legislação... porque eu e os distribuidores trabalhamos assim? Pelo giro do produto... então receber com menos de 12 meses significa que o meu operador logístico vai mandar para o operador logístico do distribuidor, o operador logístico do distribuidor vai distribuir isso pelo Brasil [...] o tempo disto e a venda disto é um risco para um negócio do distribuidor de produtos farmacêuticos.

Como visto, a indústria farmacêutica possui em seus processos operacionais apenas o desenho do fluxo reverso de medicamentos que estejam fora da possibilidade de venda, o que, segundo Lacerda (2003), Leite (2003), Zhu e Sarkis (2004), Strehlau e Telles (2006), pode ser incluído como atividade básica do fluxo reverso. Também demonstraram não possuir nenhum processo ou fluxo reverso que vise o atendimento da PNRS. O que trará uma possível dificuldade em um rápido atendimento à PNRS, por outro lado, pode ser uma oportunidade de se instaurar um processo padronizado em todas as empresas.

Diante da revisão da literatura, das análises e compreensão das entrevistas realizadas, foram identificados direcionadores de logística reversa de medicamentos com uso domiciliar, conforme Quadro 1.

Quadro 1. Mapeamento dos Direcionadores de Logística Reversa na Indústria Farmacêutica

(Continua)

\begin{tabular}{|l|l|l|}
\hline \multicolumn{1}{|c|}{ Stakebolder } & \multicolumn{1}{c|}{ Dimensão } & \multicolumn{1}{c|}{ Autores } \\
\hline Clientes & $\begin{array}{l}\text { Mercadológica: Imagem } \\
\text { diferenciada. }\end{array}$ & $\begin{array}{l}\text { Dowlatshahi (2000); Quintão e Jesus } \\
(2011) .\end{array}$ \\
\hline Pessoas envolvidas & $\begin{array}{l}\text { Operacional: Processo, } \\
\text { factibilidade, tempo, eficiência. }\end{array}$ & $\begin{array}{l}\text { Dowlatshahi (2000); Quintão e Jesus } \\
(2011) .\end{array}$ \\
\hline
\end{tabular}


(conclusão)

\begin{tabular}{|l|l|l|}
\hline \multicolumn{1}{|c|}{ Stakebolder } & \multicolumn{1}{c|}{ Dimensão } & \multicolumn{1}{c|}{ Autores } \\
\hline $\begin{array}{l}\text { Acionistas e } \\
\text { Proprietários }\end{array}$ & Financeira: Custos envolvidos. & $\begin{array}{l}\text { Dowlatshahi (2000); Roger e Tibben- } \\
\text { Lembke (2001); Stock (2007); Leite } \\
(2010) .\end{array}$ \\
\hline $\begin{array}{l}\text { Governo (Poder } \\
\text { público) }\end{array}$ & Legal: Legislação e fiscalização. & $\begin{array}{l}\text { Roger e Tibben-Lembke (2001); Stock } \\
(2007) ; \text { Leite (2010); Quintão e Jesus } \\
(2011) .\end{array}$ \\
\hline
\end{tabular}

Fonte: Elaborado pelos autores.

Nas empresas entrevistadas, alguns direcionadores mostram-se mais relevantes como, por exemplo, a influência mercadológica, situação em que se busca atender a necessidade do cliente de não possuir medicamento vencido ou que não esteja em condição de comercialização em seu estabelecimento. Também é observada a questão financeira, na qual os custos com o fluxo reverso são grandes pontos de dúvidas para a implantação da logística reversa para atendimento da PNRS.

A identificação dos fluxos reversos atualmente existentes na cadeia de medicamentos de uso domiciliar atende ao segundo objetivo específico do presente trabalho.

\subsection{PAPEL DOS FABRICANTES DE MEDICAMENTOS NO ATENDIMENTO DA PNRS}

Apesar de não estar explícito o papel da indústria farmacêutica na PNRS, o Sindusfarma tem liderado o grupo de discussão sobre este tema. A proposição de requisitos que atendam aos interesses da indústria e facilitem a implementação da logística reversa neste setor são os principais pontos, uma vez que o sindicato e os fabricantes de medicamentos entendem que nem todo medicamento é perigoso e causa problemas ambientais.

Sindusfarma: Por isso estamos pedindo agora... a nossa proposta de trabalho com o Ministério do Meio Ambiente é fazer uma classificação de periculosidade dos medicamentos. Por que? Porque nem todo medicamento é perigoso [...] por exemplo, a vitamina [...] eu posso jogar a vitamina aqui na minha planta $[. .$.$] não tem proble-$ ma nenhum $[. .$.$] estes medicamentos do tipo soro fisiológicos, soro$ 
glicosado, produto fitoterápico [...] eles não têm perigo nenhum, assim como outros fármacos. Então estamos caminhando para que tenhamos uma classificação de risco, de perigo. [...]

No contexto, foi inserido o tema da responsabilidade compartilhada. Com relação a essa questão, os entrevistados entenderam que não há possibilidade de um projeto grande como este ser desenvolvido individualmente, portanto, haveria a necessidade do envolvimento de todos os elos neste processo, inclusive do consumidor final, mesmo sabendo da falta de consciência do consumidor sobre o descarte correto dos medicamentos.

E1: Eu tenho uma opinião de trabalhar em conjunto, acho que a empresa faz isso e tem feito com outras empresas, buscando sinergia na logística, eu acredito que através de políticas governamentais de incentivo para o consumidor entender a importância [...]

Sindusfarma: Este plano deve ser feito e comunicado em conjunto. [...] todos esses elos têm seus deveres e suas responsabilidades. Até porque todos os elos auferem algum benefício neste processo $[\ldots]$ a indústria, o distribuidor e a farmácia quando vendem, o consumidor quando usa $[\ldots .$.$] e é claro o governo, porque a carga tributária de$ medicamentos é altíssima

Quando questionados se a indústria farmacêutica está preparada para o atendimento da PNRS, os entrevistados ainda não possuem uma posição clara sobre este tema.

E1: [...] fazer uma coleta em uma residência de todos os produtos passíveis de coleta de todas as indústrias farmacêuticas e aí a gente trabalha com o Sindusfarma para orientar, pois todos têm os mesmos elos de distribuição e que eu acredito que seja um caminho interessante para fazer isto.

E2: [...] hoje ele está muito voltado para a questão de se ter uma padronização em um processo que suporte/sustente as operações de logística reversa das indústrias farmacêuticas perante a nova legislação. Essa é a preocupação do sindicato. É como normatizar uma política e ter processos sustentáveis. Então, esta é a preocupação do sindicato que representa as indústrias farmacêuticas.

E3: Como te falei, as indústrias farmacêuticas seguirão as diretrizes apontadas pela Interfarma e Sindusfarma. 
Já que o assunto ainda está em pauta de discussão pelo Sindusfarma.

\begin{abstract}
Sindusfarma: Logística Reversa se aplica a estes bens que possuem uma capacidade de recuperação e reciclagem, então, se você falar uma geladeira, por exemplo, existe a possibilidade de recuperação ou reciclagem, então aí sim se aplica a logística reversa, pois os materiais retornam ao início da cadeia produtiva, gerando algum resultado. [...] para o medicamento isto não existe, tudo isto deve ser incinerado. Destinação ambiental adequada para os resíduos de medicamentos domiciliares é a incineração, uma vez que não existe forma de recuperação [...].
\end{abstract}

Nota-se que para a indústria farmacêutica, o atendimento à PNRS será um desafio que deve ser atendido em médio ou longo prazo. Ademais, percebeu-se um equívoco na visão do sindicato de que o retorno dos medicamentos não utilizados com o objetivo de incineração não constitui um processo de logística reversa.

\title{
4.4 DESAFIOS PARA O ATENDIMENTO E IMPLEMENTAÇÃO DA PNRS
}

Apesar da experiência da indústria farmacêutica em processos de logística reversa de medicamentos, alguns desafios para o atendimento e implantação da PNRS foram identificados durante as entrevistas.

A PNRS entrou em vigor em 2010 e, conforme o artigo 54, as empresas terão um prazo de quatro anos para se adequarem. Ao serem questionados se as empresas cumprirão o prazo estabelecido pela PNRS para a implantação dos programas de logística reversa, ou se estão aptos a atenderem as suas expectativas, a maior parte dos entrevistados afirma ser pouco provável que isto aconteça, pois o tema torna-se complexo, à medida que a PNRS não está claramente especificando os medicamentos e seus derivados.

E1: $[\ldots]$ a indústria também se conscientiza e cada vez mais ela está trazendo isso, eu acho que talvez a velocidade que precisa ser trazida não é compatível com a velocidade que as empresas estão fazendo as coisas acontecerem [...].

E3: [...] mas todas as indústrias vão fazer, vão se adequar [...] isto se não estão fazendo, mas eu vejo somente nos próximos 3 a 4 anos uma evolução muito grande no controle dos processos logísticos, tanto no de ida quanto no de volta $[\ldots]$ 
Nota-se que apesar do prazo estipulado pelo artigo 54 para adaptação, ainda não existe um consenso sobre o atendimento ou não, segundo o Sindusfarma, as discussões estão ocorrendo, mas ainda existem pontos de dúvidas sobre a lei.

Sindusfarma: [...] nós estamos discutindo este tema com a Anvisa e o Ministério do Meio Ambiente, desde abril de 2011... vai fazer aí 3 anos... e é incrível, pois os medicamentos não estão explicitamente na PNRS... é um negócio impressionante.

Outro ponto levantando foi a questão sobre as possíveis soluções e pontos de coletas para os medicamentos vencidos, de modo que a indústria farmacêutica possa ter um canal reverso específico para a coleta, que poderia ser nas farmácias, o que facilitaria ao consumidor final a entrega do medicamento, bem como a coleta pelos outros elos da cadeia responsáveis pela entrega.

E1: A farmácia seria o elo ideal para isto e farmácias, nós temos milhares pelo Brasil pra conseguir fazer isso. Como nós já temos as coletas do elo intermediário na farmácia ou no distribuidor [...] ela já faz a ida $[\ldots]$ ele fazer a volta, seria tranquilo $[. .$.$] inclusive, ele$ aproveitaria o caminhão para uma carga. Hoje muitos trechos que fazemos, na ida há volume e na volta perdemos dinheiro com o caminhão vazio.

E2: [...] e onde serão os postos de coleta? Isso tem que ficar muito fácil, tem que haver uma desburocratização... eu posso ter comprado um remédio em São Paulo e posso estar descartando no Estado do Rio de Janeiro, em qualquer farmácia [...] é então aí que vem o ponto que tudo tem que estar muito facilitado, tem que funcionar a logística reversa com muita naturalidade.

No entanto, na visão do Sindusfarma existem outras possibilidades de executar a logística reversa destes medicamentos, onerando menos a cadeia e reduzindo possíveis contaminações ambientais e sanitárias decorrentes do acúmulo de resíduos nas farmácias e da posterior movimentação.

Sindusfarma: [...] é claro que ter a urna lá é bom, mas o custo envolvido é muito maior que se realizar uma campanha. [...] Uma das ideias também é fazer algo como campos de coleta, nos EUA tem um negócio chamado the backpack day, isto é, o dia do retorno, uma semana ou 15 dias [...], você monta toda uma estrutura, leva todas as empresas responsáveis pelos produtos, leva empresas de 
reciclagem, faz campanhas para que as pessoas levem os produtos para a reciclagem e as empresas já encaminham para o descarte ou reciclagem corretamente $[\ldots]$

No contexto da discussão, abriu-se um tópico de análise de viabilidade econômica na implantação deste processo de logística reversa. Os entrevistados apontaram que atualmente a indústria arca com os custos dos retornos, porém, existe a facilidade da identificação do produto, do cliente, da causa e do momento da devolução, o que não deve ocorrer em um processo de logística reversa de pósconsumo.

E1: Está na indústria o custo [..] porque esta responsabilidade de retorno é minha $[. .$.

E2: [...] o ponto que você citou logo no início, (custo logístico), eu acho que ele vai ser o ponto de barreira... nem tanto para as grandes indústrias... todas terão impactos, umas mais outras menos. Isso é tema que vai dar uma boa margem de discussão [...] mas se a indústria farmacêutica entender que ela deveria pagar, qual é a contrapartida que ela pode ter pra não sofrer prejuízos?

E3: [...] o ponto da questão da logística reversa é como fazer esta reversa de fato funcionar até as suas indústrias esses produtos. Como chegar de uma forma desburocratizada [...]

Sindusfarma: A reciclagem no Brasil é cara, não existe um material reciclado que seja mais barato que o virgem, todos os materiais oriundos da reciclagem são mais caros e alguns ainda não têm a viabilidade técnica ainda. No papel é muito bonito, os discursos das pessoas, os ambientalistas, mas na prática [...]

Como visto nos discursos, os custos em operações logísticas ainda são onerosos para a cadeia de suprimentos, tanto a de distribuição, quanto a de retorno, porém é um determinante importante para que estes processos ocorram da melhor forma possível, o que corrobora com as teorias de Lambert, Cooper e Pagh (1998).

A partir dos recortes e observações acima apresentados, constata-se que o debate sobre os desafios da implantação da logística reversa para medicamentos com uso domiciliar influenciada pela PNRS está sendo tratado no país. Os entrevistados avaliam como muito importante o conteúdo da política, no entanto, por ser de um processo complexo, lento e conflituoso, ainda demandará algum tempo para a indústria farmacêutica se adaptar. Ademais, o aspecto financeiro surge como mais 
relevante nas discussões sobre a estruturação de processos de logística reversa e no atendimento à PNRS por parte do setor.

\section{CONSIDERAÇÕES FINAIS}

Esse artigo teve o objetivo geral de analisar a influência da PNRS na logística reversa da indústria farmacêutica de medicamentos de uso domiciliar, constituindo um estudo qualitativo de caráter descritivo, que envolveu a realização de entrevistas em profundidade com gestores de três empresas da indústria farmacêutica, bem como o SINDUSFARMA, já que, durante a execução das entrevistas com os gestores, identificou-se que o sindicato exerce um papel de liderança nas discussões relacionadas ao atendimento ao que está previsto na PNRS. Uma das contribuições emerge dos resultados encontrados, quando verificado que as empresas do setor farmacêutico estão se reunindo e nomeando um representante de classe para que lidere as negociações e dissemine para todas as empresas o melhor processo para atender a PNRS.

Em linhas gerais, constatou-se que a indústria farmacêutica possui grandes desafios para a implementação da PNRS. A conscientização do consumidor final no processo aparece como sendo um ponto importante no processo de constituição do fluxo reverso, além da questão dos custos operacionais envolvidos, uma vez que a indústria farmacêutica não está totalmente preparada. Existe um extenso conjunto de empresas que participam da cadeia de suprimentos da indústria farmacêutica, os quais necessitam gerenciar todo o resíduo gerado ao longo da cadeia.

Outro importante resultado da pesquisa para a sociedade foi a necessidade da educação ambiental e a consciência do consumidor sobre o descarte correto de seus resíduos, que foram também destacados durante as entrevistas. Ademais, a informatização e a rastreabilidade durante o processo de distribuição dos medicamentos podem auxiliar a implantação de um processo de logística reversa mais robusto e coerente com as demandas da PNRS. A pesquisa também fornece a visão que a indústria farmacêutica ainda não está totalmente preparada para o atendimento à PNRS, já que existem ainda diversos desafios que precisam ser 
ultrapassados nas discussões sobre o tema. Algumas ações pontuais estão sendo feitas, mas ainda necessitam de obter o apoio de toda a indústria e sua cadeia de suprimentos.

A partir dessa investigação foi possível ampliar a compreensão de problemas envolvendo a logística reversa de medicamentos de uso domiciliar. As informações analisadas demonstram que o marco regulatório instituído pela PNRS possui diretrizes importantes para a implementação da logística reversa de medicamentos, embora ainda não se perceba a efetiva busca pelo cumprimento dessas diretrizes.

Espera-se, também, que essa compreensão propicie o desenvolvimento de novos estudos para melhor compreensão do tema proposto. Recomenda-se a inclusão de novos atores, como, por exemplo, as redes de farmácias e o poder público, de modo que se aumente o escopo da pesquisa e sejam incluídas todas as visões de diversos componentes da cadeia de suprimentos sobre o tema estudado.

\section{REFERÊNCIAS}

ARAÚJO, L.; GAVA, R. Empresas proativas: como antecipar mudanças no mercado corporativo brasileiro. Belo Horizonte: Campos, 2011.

ANVISA. Agência Nacional de Vigilância Sanitária. RDC n ${ }^{0}$ 306/04. Aspectos Jurídicos da Resolução da Diretoria Coligada da ANVISA sobre Resíduos de Serviços de Saúde. Brasília: Ministério da Saúde. 2004. Disponível em: < http:// portal.ANVISA.gov.br/wps/wcm/connect/696fc000474583b98eb2de3fbc4c6735/ revista_ANVISA-060508.pdf?MOD=AJPERES $>$ Acesso em: 21 jan. 2014.

ATTARAN, M.; ATTARAN, S. Collaborative supply chain management. The most promising practice for building efficient and sustainable supply chains. Business Process Management Journal, v. 13, n. 3, p. 390-404, 2007.

BALLOU, R. H. Logística empresarial. São Paulo: Atlas, 1993.

BONI, V.; QUARESMA, S. J. Aprendendo a entrevistar: como fazer entrevistas em ciências sociais. Revista Em Tese, UFSC, v. 2, n. 1, p. 68-80, 2005. 
BOWERSOX, D. J.; CLOSS, D. J. Logística empresarial: o processo de integração da cadeia de suprimentos. São Paulo: Atlas, 2001.

BRASIL. Ministério da Saúde. Manual de gerenciamento de resíduos de serviço de saúde. Brasília, 2006. Disponível em: < http://www.ANVISA.gov.br/servicosaude/ manuais/manual_gerenciamento_residuos.pdf $>$. Acesso em: 03 fev. 2014.

BRASIL. Presidência da República. Lei no 12.305/2010, art. 33, $\S 1^{\circ}$. Institui a Política Nacional de Resíduos Sólidos; altera a Lei n ${ }^{\circ}$ 9.605, de 12 de fevereiro de 1998; e dá outras providências. Brasília. 2010.

COOPER, D. R.; SCHINDLER, P. S. Métodos da pesquisa em administração. 7. ed. Porto Alegre: Bookman, 2003.

DAUGHTON, C. Cradle-to-cradle stewardship of drugs for minimizing their environmental disposition while promoting human health. I. Rationale for and avenues toward a green pharmacy. Environ Health Perspect, v. 111, p. 757-774, $2003 \mathrm{a}$.

DAUGHTON, C. Cradle-to-cradle stewardship of drugs for minimizing their environmental disposition while promoting human health. II. Drug disposal, waste reduction, and future directions. Environ Health Perspect, v. 111, p. 775-785, 2003b.

DENZIN, N. K.; LINCOLN, Y. S. O Planejamento da pesquisa qualitativa: teorias e abordagens. 2. ed. Porto Alegre: Bookman, 2006.

DONATO, V. Logística verde: uma abordagem socioambiental. Rio de Janeiro: Ciência Moderna, 2008.

DOWLATSHAHI, S. Developing a theory of reverse logistics. Interfaces, v. 30, n. 3, p. $143-145,2000$.

GASKELL, G. Entrevistas individuais e grupais. In: BAUER, M. W.; GASKELL, G. (Org.). Pesquisa qualitativa com texto, imagem e som: um manual prático. Petrópolis: Vozes, 2002. 
GODOY, A. S. A pesquisa qualitativa: tipos fundamentais. RAE - Revista de Administração de Empresas, São Paulo, v. 35, n. 3, p. 20-29, 1995 a.

GODOY, A. S. A pesquisa qualitativa e sua utilização em administração de empresas. RAE - Revista de Administração de Empresas, São Paulo, v. 35, n. 4, p. 65-71, 1995b.

HIRATUKA, C.; VARGAS, M. A.; FRACALANZA, P.; ROSADISNKI, E. N.; CORAZZA, R. I.; OLIVEIRA, A. L. R.; LUNA, I. Logística reversa para o setor de medicamentos. Brasília: ABDI, 2013.

KUMAR, S.; PUTNAM, V. Cradle to cradle: reverse logistics strategies and opportunities across three industry sectors. International Journal of Production, v. 115, n. 2, p. 305-315, 2008.

KUMAR, S.; DIEVENEY, E.; DIEVENEY, A. Reverse logistic process control measures for the pharmaceutical industry supply chain. International Journal of Productivity and Performance Management, v. 58, n. 2, p.188-204, 2009.

LACERDA, L. Logística reversa: uma visão sobre os conceitos básicos e as práticas operacionais. In: FIGUEIREDO, K. F.; FLEURY, P. F.; WANKE, P. (Org.). Logística e gerenciamento da cadeia de suprimentos: planejamento do fluxo de produtos e dos recursos. Centro de Estudos em Logística. COPPEAD, UFRJ. São Paulo: Atlas, 2003.

LAMBERT, D. M.; COOPER, M. C.; PAGH, J. D. Supply chain: implementation, issues and research opportunities. The International Journal of Logistics Management, v. 9, n. 2, p. 1-19, 1998.

LAMBERT, D. M.; COOPER, M. C. Issues in supply chain management. Industrial Marketing Management, v. 29, p. 65-83, 2000.

LEITE, P. R. Logística Reversa. São Paulo: Prentice Hall Brasil, 2003.

LEITE, P. R. Empresas brasileiras adotam políticas de logística reversa relacionada 
com o motivo de retorno e com o direcionador estratégico? In: ENCONTRO DA ASSOCIAÇÃO NACIONAL DE PÓS-GRADUAÇÃO EM ADMINISTRAÇÃO, 34., 2010, Rio de Janeiro. Anais... Rio de Janeiro: ANPAD, 2010.

MISHRA, N.; KUMAR, V.; CHAN, F. T. S. A multi-agent architecture for reverse logistics in a green supply chain. International Journal of Production Research. v. 50, n. 9, p. 2396-2406, 2012.

NOVAES, A. G. Logística e gerenciamento da cadeia de distribuição. Rio de Janeiro: Elsevier, 2007.

PALMEIRA-FILHO, P. L.; CAPANEMA, L. X. L. A indústria farmacêutica nacional: desafios rumo à inserção global. BNDES Setorial, n. 19. p. 307-318. 2010.

QUINTÃO, R. T.; JESUS, L. F. N. Determinantes da Realização da Logística Reversa no Setor Supermercadista. In: ENCONTRO NACIONAL DOS PROGRAMAS DE PÓSGRADUAÇÃO EM ADMINISTRAÇÃO, 35, 2011, Rio de Janeiro. Anais.... Rio de Janeiro: ANPAD, 2011.

REVEILlEAU, A. C. A. Política Nacional de Resíduos Sólidos: aspectos da responsabilidade dos geradores na cadeia do ciclo de vida do produto. Revista Internacional de Direito e Cidadania, n. 10, p. 163-174, 2011.

ROGERS, D. S.; TIBBEN-LEMBKE, R. S. An examination of reverse logistics practices. Journal of Business Logistics, v. 22, n. 2, p. 129-148, 2001.

SEURING, S.; SARKIS, J.; MULLER, M.; RAO, P. Sustainability and supply chain management - an introduction to the special issue. Journal of Cleaner Production, v. 16. p. 1545-1551. 2008.

SRIVASTAVA, S. Green supply-chain management: A state-of the-art literature review. International Journal of Management Reviews. v. 9, n. 1, p. 53-80, 2007.

STOCK, J. R. Reverse logistics in the supply chain. Transport \& Logistics Magazine, p. 44-48, 2007. 
STREHLAU, V. I.; TELLES, R. Canais de marketing \& distribuição: conceitos, estratégias, gestão, modelos de decisão. São Paulo: Saraiva, 2006.

THIERRY, M.; SALOMON, M.; van NUNEN, J.; van WASSENHOVE, L. Strategic issues in product recovery management. California Management Review, v. 37, n. 2, p. 114-135. 1995.

TIBBEN-LEMBKE, R. S.; ROGERS, D. S. Differences between forwards and reverses logistics in a retail environment. Supply Chain Management: An International Journal, v. 7, n. 5, p. 271-282, 2002.

ZHU, Q.; SARKIS, J. Relationships between operational practices and performance among early adopters of green supply chain management practices in Chinese manufacturing enterprises. Journal of Operations Management, v. 22, n. 3, p. 265-289, 2004.

Recebido em: 23 de julbo de 2015 Aceito em: 21 de janeiro de 2016 